\title{
The relationship of leukoaraiosis, haemorrhagic transformation and prognosis at 3 months after intravenous thrombolysis in elderly patients aged $\geq 60$ years with acute cerebral infarction
}

\author{
Xiaowei Liu ${ }^{1,2,3} \cdot$ Jiatang Zhang ${ }^{1,2} \cdot$ Chenglin Tian $^{2} \cdot$ Jun Wang ${ }^{2}$ \\ Received: 31 August 2019 / Accepted: 6 April 2020 / Published online: 1 May 2020 \\ (C) The Author(s) 2020
}

\begin{abstract}
Backgroud As the elderly stroke population continues to increase, we will have to confront greater challenges regarding how to choose suitable patients to reduce thrombolysis-related bleeding events and accurately judge their prognosis. Therefore, we evaluated the relationship among leukoaraiosis (LA), haemorrhagic transformation (HT) and the prognosis at 3 months after intravenous (IV) thrombolysis in elderly patients aged $\geq 60$ years with acute cerebral infarction (ACI).

Methods We prospectively and consecutively chose 125 elderly patients aged $\geq 60$ years with ACI who could accept and be suitable for IV recombinant tissue plasminogen activator (rtPA) after excluding 6 cases. Brain computed tomography(CT) was used to assess LA by using the modified Van Swieten scale (mVSS) before treatment and the modified Rankin scale (mRS) to appraise prognosis at 3 months after IV rtPA. Binary logistic regression was used to analyse the predictors of HT and the prognosis of ACI.

Results Our data indicated that by brain CT, 26.4\% of all patients showed severe LA, and the rate of HT and symptomatic intracranial haemorrhage (sICH) were $12.0 \%$ and $9.6 \%$, respectively. Severe LA was evidently associated with HT (odds ratio [OR] 3.272, 95\% confidence interval [CI] 1.010-10.598, $P=0.048)$ rather $\mathrm{sICH}(P>0.05)$. Moreover, we also found that severe LA was associated with poor functional prognosis (OR 5.266, 95\% CI 1.592-17.419, $P=0.006$ ).

Conclusion Our results showed that LA was associated with HT and adverse clinical prognosis rather sICH after IV rtPA in elderly patients aged $\geq 60$ years with ACI. Although LA may increase the risk of bleeding but not fatal haemorrhage after IV thrombolysis, therefore, we should actively select an appropriate elderly population for thrombolytic treatment and have reasonable judgments on the outcomes.
\end{abstract}

Keywords Leukoaraiosis $\cdot$ Haemorrhagic transformation $\cdot$ Prognosis $\cdot$ Intravenous thrombolytic $\cdot$ Ischemic stroke $\cdot$ Geriatric

\section{Introduction}

It is well-known that IV thrombolysis in the hyperacute phase with rtPA recommended according to current guidelines [1] is one of the most effective ways to treat $\mathrm{ACI}$, which can reduce

Jiatang Zhang

zhangjt1128@sina.com

1 Medical School of Chinese PLA, Medical School of Chinese PLA, Beijing, China

2 Chinese PLA General Hospital, No. 28, Fuxing Road, Beijing 100853, China

3 Beijing Huairou Hospital, No.9, Yongtai North Street, Beijing 101400, China the stroke-related disability and mortality. However, this treatment has some serious complications, such as HT even fatal sICH [2], which can affect the clinicians' treatment decisions. Whether LA will increase the risks of HT and adverse prognoses after IV rtPA is still controversial [3-6]. As the life expectancy of human beings continues to gradually increase, so too does the number of elderly patients with ACI [7]. Fortunately, elderly ACI patients can benefit from thrombolytic therapy [8]. However, LA is more common in geriatric populations than in young people [9]. Whether the risk of HT in elderly patients with LA increases after IV rtPA is uncertain, and the prognosis of these patients at 3 months also needs to be further assessed. The purpose of the present study was to better understand the above relationships in elderly patients aged $\geq 60$ years with ACI. 


\section{Methods}

From January 2016 to December 2018, 131 patients with ACI who were aged $\geq 60$ years and were to be treated with IV rtPA within $4.5 \mathrm{~h}$ after stroke attacked were continuously selected in the Huairou District of Beijing. The inclusion and exclusion criteria of National Institute of Neurological Disorders and Stroke (NINDS) in 1995 were consulted [2], but no upper age limit was applied. Basic demographic characteristics and clinical history (including hypertension, diabetes mellitus, pre-stroke, coronary heart disease(CHD), congestive heart failure(CHF), atrial fibrillation(AF), smoking, hyperlipidaemia, chronic kidney disease(CKD), pre-anticoagulate/antiplatelet therapy(Pre-AC/AP)) were recorded. Before IV rtPA, National Institutes of Health Stroke Scale (NIHSS) were assessed by two senior neurologists simultaneously; in the cases of inconsistency, a superior neurologist adjudicated. At 3 months after thrombolytic therapy, two other senior neurologists without any knowledge of the clinical information evaluated the patients' functional prognosis by face-to-face or telephone interview. MRS scores were used to grade the functional prognosis, where a score of $0-1$ points was considered good, and a score of 2 or more points was considered bad. All of the selected patients were given rtPA $(0.6-0.9 \mathrm{~g} / \mathrm{kg}$ according to the standard dose, with $10 \%$ of the dose bolus injected within $1 \mathrm{~min}$ and the remaining $90 \%$ pumped over the course of an hour). All patients were routinely examined by brain CT at $24 \mathrm{~h}$ except one dead of sICH within $1 \mathrm{~h}$ after treatment, and 91 patients were examined by magnetic resonance imaging (MRI) within $36 \mathrm{~h}$ after thrombolysis, and those whose symptoms deteriorated or who had suspicious bleeding were checked by CT at any time to exclude intracranial haemorrhage. HT was evaluated according to the European Cooperative Acute Stroke Study-II (ECASSII) criteria [10]. The images of the HT were read by two other senior radiologists who were completely blinded to the clinical information. If there was disagreement, more experienced radiologists were called in to make a decision. MVSS [11] was used to classify white matter lesions. Scores between 1 and 4 were classified as mild lesions, and scores greater than 4 scores were classified as severe lesions. The mVSS score was graded by two other senior radiologists who were fully blind to patients. In cases of disagreements, a more senior radiologist was called in to resolve the assessment. All patients signed informed consent and were approved by the Ethics Committee.

\section{Statistics}

All data were analysed by using the SPSS 17.0 software package (SPSS Inc. Chicago, IL, USA). Measured data was assessed by ANOVA or a T test, and numeration data was assessed by a Chi-squared test. The relationships between variables were analysed by correlation and logistic regression analysis. $P<0.05$ was considered significant.

\section{Results}

A total of 131 eligible patients were enrolled, 6 cases of which were lost due to transfer or abandonment of treatment ( 5 cases in the non-mild group and 1 case in the severe group). The mean age was 73.2 years. The basic information is shown in Table 1. There were 43 patients without white matter lesions (34.4\%), 49 patients with mild white matter lesions $(39.2 \%)$ and 33 patients with severe white matter lesions $(26.4 \%)$. According to the severity of the white matter lesions, the patients were divided into two groups (the non-mild lesion group and the severe lesion group). The baseline data of the two groups were not significantly different except for age and NIHSS score before thrombolysis $(P=0.02$ and 0.02 , respectively), as shown in Table 2. There were 15 patients $(12.0 \%$, $15 / 125)$ with haemorrhagic transformation after IV, including 12 cases $(9.6 \%, 12 / 125)$ of sICH. Correlation analysis indicated that HT was related to LA, NIHSS score (severity of stroke) and congestive heart failure (CHF). After adjusting for confounding factors, binary logistic analysis indicated that LA were associated with HT and NIHSS (NIHSS scores $\geq 12$ means severity), $(P=0.048$, OR 3.272 , 95\% CI 1.010 10.598; $P=0.012$, OR 5.042, 95\% CI 1.434-17.272, respectively), as shown in Table 3 . There were 47 cases with mRS scores $<2$ and 45 cases with scores $\geq 2$ at 3 months after IV in the non-mild LA group. In the severe LA group, there were 5 cases with mRS scores $<2$ and 28 cases with scores $\geq 2$.
Table 1 Baseline characteristics

\begin{tabular}{ll}
\hline All patients & $n=125, N(\%)$ \\
\hline Age(mean) & $73.2 \pm 8.2$ \\
Sex(female) & $41(32.8)$ \\
NIHSS & $10.5(2-38)$ \\
Hypertension & $79(63.2)$ \\
Diabetes & $28(22.4)$ \\
Pre-stroke & $37(29.6)$ \\
CHD & $53(42.4)$ \\
CHF & $19(15.2)$ \\
AF & $29(23.2)$ \\
Cigar & $48(38.4)$ \\
Hyperlipidaemia & $30(24)$ \\
CKD & $4(3.2)$ \\
Pre-AC/AP & $44(35.2)$ \\
LA & \\
0 & $43(34.4)$ \\
$1-4$ & $49(39.2)$ \\
$5-8$ & $33(26.4)$ \\
\hline
\end{tabular}


Table 2 Non-mild LA and severe LA groups baseline

\begin{tabular}{llll}
\hline & Non-mild & Severe & $P$ value \\
\hline Sex(male) & 63 & 21 & 0.611 \\
Age & $71.8 \pm 8.3$ & $76.9 \pm 7.5$ & $0.02^{\mathrm{a}}$ \\
NIHSS & $9.6 \pm 7.7$ & $13.2 \pm 7.5$ & $0.024^{\mathrm{b}}$ \\
Hypertension & 55 & 24 & 0.186 \\
Diabetes & 20 & 8 & 0.767 \\
Pre-stroke & 28 & 9 & 0.733 \\
CHD & 36 & 17 & 0.217 \\
CHF & 12 & 7 & 0.262 \\
AF & 18 & 11 & 0.108 \\
Cigar & 35 & 13 & 0.891 \\
Hyperlipidaemia & 20 & 10 & 0.323 \\
CKD & 3 & 1 & 1.000 \\
Pre-AC/AP & 32 & 12 & 0.870 \\
\hline
\end{tabular}

$a$ and $b$ have statistical significance

Binary logistic analysis showed that $\mathrm{mRS}$ score $>2$ was related to the severity of stroke $(P<0.01$; OR $9.594,95 \% \mathrm{CI}$ 3.133-29.378) and LA $(P=0.006$; OR 5.266, $95 \% \mathrm{CI}$ 1.592-17.419), as shown in Table 4.

\section{Conclusion}

LA is associated with HT rather sICH and the prognosis at 3 months in elderly patients aged $\geq 60$ years following IV rtPA in the Huairou District of Beijing. The severe LA may increase the risk of HT and the worse outcome at 3 months after thrombolytic therapy.

\section{Discussions}

LA was first proposed by Hanchski in 1987 [12], and it was mainly described by imaging: low white matter density on brain CT, and high white matter signal on MRI T2 and Flair images. A previous study suggested that LA was associated with cognitive impairment/dementia and stroke risk [13]. With the increasing awareness of super-acute IV rtPA for stroke, we are confronting more and more risks for this therapy. Whether LA increases the risk of haemorrhage after

Table 3 Factors related toHT

\begin{tabular}{llll}
\hline & OR & $95 \% \mathrm{CI}$ & $P$ value \\
\hline NIHSS & 5.042 & $1.434-17.727$ & $0.012^{\mathrm{a}}$ \\
CHF & 0.456 & $0.121-1.723$ & 0.247 \\
LA & 3.272 & $1.010-10.598$ & $0.048^{\mathrm{b}}$ \\
\hline
\end{tabular}

$a$ and $b$ have statistical significance
Table 4 Factors related to prognosis

\begin{tabular}{llll}
\hline & OR & $95 \% \mathrm{CI}$ & $P$ value \\
\hline Age & 1.026 & $0.967-1.089$ & 0.394 \\
NIHSS & 9.594 & $3.133-29.378$ & $0.000^{\mathrm{a}}$ \\
CHD & 0.539 & $0.198-1.469$ & 0.227 \\
CHF & 0.464 & $0.429-10.845$ & 0.351 \\
LA & 5.266 & $1.592-17.419$ & $0.006^{\mathrm{b}}$ \\
HT & 5.290 & $0.529-52.844$ & 0.156 \\
\hline
\end{tabular}

$\mathrm{a}$ and $\mathrm{b}$ have statistical significance

thrombolysis is one of these inevitably realistic problems. As a common type of cerebral small vessel disease [14], LA incidence increases with age, and some studies suggest that it increases 2.4-fold every 10 years [9]. As the human lifespan continues to increase, the elderly may become a large proportion of patients receiving IV rtPA. For these populations, we should carefully wield the double-edged sword of thrombolytic treatment to provide the most suitable treatment strategies, improve their quality of life and reduce their social and financial burdens.

Most researches on LA and haemorrhagic transformation after thrombolysis has essentially arrived at a unanimous conclusion, which is that severe LA increases the occurrence of HT or sICH after thrombolysis [3, 15-17]. A similar result was observed from a meta-analysis in 2017 [18]. However, a few studies have reported contradictory results [5, 19]. Relevant research is extremely scarce in China, even in Asians, and such data on the elderly have rarely been reported. Yang et al. [20] obtained a negative correlation between LA and sICH, and their study was based on adults from Taiwan published in 2018. Is there a relationship between LA and sICH or HT in the Chinese population? What is the outcome for the growing proportion of elderly individuals? We carried out this study to answer these questions.

Our results showed that severe white matter lesions in elderly individuals aged $\geq 60$ years increased the risk of HT but not sICH after IV rtPA and the latter accounting for a $9.6 \%$ incidence among all our patients. The incidence of sICH was higher than the $6.4 \%$ from NINDS [2] and the $7.2 \%$ from Alteplase Thrombolysis for Acute Non-interventional Therapy in Ischemic Stroke (ATLANTIS) [21], is similar to the $8.8 \%$ from ECASSII [10] and is slightly lower than the $10.8 \%$ from Prolyse in Acute Cerebral Thromboembolism-II (PROACTII) [22]. The reason for the higher proportion compared with the NINDS and ATLANTIS studies lies in the difference in the selected populations. The NINDS study only contained a few elderly people, and the ATLANTIS study excluded patients over 80 years; in contrast, our study focused on all elderly patients aged $\geq 60$ years, among whom the oldest age was 96 years. A previous study indicated that the risk of haemorrhage following IV rtPA increased with age 
[23]. Certainly, the rate of sICH in the Asian population might actually be higher than that in Western countries [24]. Prior research has revealed that the severity of stroke increases the risk ratio of haemorrhage after thrombolysis [25]. The stroke severity observed in the PROACTII study was greater than ours; the average NIHSS score of the PROACTII study was 17 , while our average score was approximately 11 . This may account for why our sICH incidence was lower than theirs. Our results about the relationship of LA and HT were consistent with other existing studies [26-28], but the proportion of severe LA (35.9\%) from France [28] was higher than ours (26.4\%). There are two explanations for this difference: first, their sample consisted of an older population (aged over 75 years) than ours, and second, their imaging assessments were based on MRI, through which the detection rate of LA may be higher than our based on brain CT because of sensitivity [29]. Meanwhile we tried our best to adopt a uniform LA score system (mVSS) [11,20], the results about the correlation of LA and sICH were accordant to the data from Taiwan in China [20]. Although all eligible adults presenting with acute stroke and receiving IV rtPA accepted in their research were younger (mean age approximately 67 years old) than ours (mean age approximately 73 years old), the final result was the same. Our correlation analysis simultaneously suggested that the severity of stroke and CHF in elderly patients were related to HT, but after binary regression analysis, only LA and NIHSS became the factors affecting the outcome. Therefore, the present study indicated that LA and severity of stroke in elderly patients were likely to influence HT independent of other risks after IV rtPA. We further analysed the relationship between $\mathrm{LA}$ and $\mathrm{sICH}$, and the results were not related $(P>0.05)$. In summary we should pay more attention to and carefully evaluate patients before IV rtPA and actively adopted this treatment confronting elderly individuals with LA, including severe LA.

Plenty of researches had reported that LA is related to cerebral ischaemia, insufficient perfusion [30], venous collagenosis [31], genetic factors [32] and increased permeability of the blood-brain barrier (BBB) [33]. Animal experiments have shown that intravenous application of alteplase aggravated the destruction of the BBB in a suture occlusion model in rats [34]. These proofs may be the theoretical basis for the finding that patients with ACI accompanied by LA were more prone to HT after IV rtPA.

Our data also showed that LA was associated with adverse prognosis at 3 months after IV rtPA in elderly. This result is compatible with the conclusions of Western studies [27, 35]. The meta-analysis [27] suggested that LA doubled the incidence of poor outcomes at 3 months after IV rtPA. Our results on prognosis following thrombolytic treatment were consistent with those from Taiwan in China [20] and the outcomes reported in a Korean population [3]. White matter lesions impair the neuronal network between brain cells and synapses and ultimately affect the 3 months of functional recovery, which may be the reason for the effect of LA on bad prognosis [36].

Our study is a prospective observational study, and the subject population consisted of elderly individuals aged $\geq$ 60 years. At present, there are few similar studies on the relationship between LA, HT and prognosis at 3 months after IV rtPA in the elderly population, which is the greatest advantage of this study. Meanwhile, we strictly guaranteed the quality and authenticity of the data through measures such as blinded analyses, which included blindness between testers and subjects and between individual testers.

However, this study also has some shortcomings. First, we conducted only a single-centre study, and we had a small sample size that included 6 loss cases, which might have an impact on the outcome to some extent. Therefore, it is necessary to conduct additional, multi-centre, large-sample studies to provide additional evidence for our conclusions. Our hospital is the only stroke medical centre with thrombolytic qualification in the Huairou District of Beijing; thus, our data were integrated, which may reduce selective bias from patients to the maximum extent. Second, we used a brain CT scan to assess LA, which is less sensitive to head MRI and might cause underestimation of LA. However, CT scan is simpler and easier to perform, which is more suitable for elderly patients with severe illness or metal implants who cannot submit to head MRI examination. Thus, our examination would not only lessen sample selective bias for the above reasons but also greatly minimize the time delay for thrombolytic therapy because of its simplicity and practicality. Last, our study was observational one, and we need more convincing evidence from further RCT research.

In summary, we concluded that LA is associated with HT rather sICH and poor clinical prognosis after IV rtPA in elderly patients aged $\geq 60$ years with ACI in the Huairou District of Beijing: the severe LA may increase the risk of HT and the worse prognosis at 3 months after thrombolytic treatment. When implementing IV rtPA, we should pay more attention to the complications of HT for elderly acute stroke patients with LA, but this should not affect clinicians' treatment decisions. At the same time, we should strive to attain preliminary and accurate prediction of the prognosis for this population.

\section{Compliance with ethical standards}

Conflict of interest The authors declare that they have no conflict of interest.

Ethical approval The study was approved by the Institutional Ethical Committee of Beijing Huairou Hospital. All of the procedures were performed in accordance with the Declaration of Helsinki and relevant policies in China.

Informed consent We have obtained written informed consent from all study participants. 
Open Access This article is licensed under a Creative Commons Attribution 4.0 International License, which permits use, sharing, adaptation, distribution and reproduction in any medium or format, as long as you give appropriate credit to the original author(s) and the source, provide a link to the Creative Commons licence, and indicate if changes were made. The images or other third party material in this article are included in the article's Creative Commons licence, unless indicated otherwise in a credit line to the material. If material is not included in the article's Creative Commons licence and your intended use is not permitted by statutory regulation or exceeds the permitted use, you will need to obtain permission directly from the copyright holder. To view a copy of this licence, visit http://creativecommons.org/licenses/by/4.0/.

\section{References}

1. Powers WJ, Rabinstein AA, Ackerson T, Adeoye OM, Bambakidis NC, Becker K, Biller J, Brown M, Demaerschalk BM, Hoh B, Jauch EC, Kidwell CS, Leslie-Mazwi TM, Ovbiagele B, Scott PA, Sheth KN, Southerland AM, Summers DV, Tirschwell DL, American Heart Association Stroke Council (2018) 2018 guidelines for the early management of patients with acute ischemic stroke: a guideline for healthcare professionals from the American Heart Association/American Stroke Association. Stroke. 49(3): e46-e110

2. National Institute of Neurological Disorders and Stroke rt-PA Stroke Study Group (1995) Tissue plasminogen activator for acute ischemic stroke. N Engl J Med 333(24):1581-1587

3. Yaghi S, Boehme AK, Dibu J, Leon Guerrero CR, Ali S, MartinSchild S, Sands KA, Noorian AR, Blum CA, Chaudhary S, Schwamm LH, Liebeskind DS, Marshall RS, Willey JZ (2015) Treatment and outcome of thrombolysis-related hemorrhage: a multicenter retrospective study. JAMA Neurol 72(12):1451-1457

4. Choi JH, Bae HJ, Cha JK (2011) Leukoaraiosis on magnetic resonance imaging is related to long-term poor functional outcome after thrombolysis in acute ischemic stroke. J Korean Neurosurg Soc 50(2):75-80

5. Demchuk AM, Khan F, Hill MD, Barber PA, Silver B, Patel S, Levine SR, NINDS rt-PA Stroke Study Group (2008) NINDS rtPA stroke study group. Importance of leukoaraiosis on CT for tissue plasminogen activator decision making: evaluation of the NINDS rt-PA stroke study. Cerebrovasc Dis 26(2):120-125

6. Palumbo V, Boulanger J, Hill M, Inzitari D, Buchan A, Investigators C (2007) Leukoaraiosis and intracerebral hemorrhage after thrombolysis in acute stroke. Neurology. 68(13):1020-1024

7. Howard G, Goff DC (2012) Population shifts and the future of stroke: forecasts of the future burden of stroke. Ann N Y Acad Sci 1268:14-20

8. Tanne D, Gorman MJ, Bates VE et al (2000) Intravenous tissue plasminogen activator for acute ischemic stroke in patients aged 80 years and older: the tPA stroke survey experience. Stroke 31(2):370-375

9. Sawada H, Udaka F, Izumi Y, Nishinaka K, Kawakami H, Nakamura S, Kameyama M (2000) Cerebral white matter lesions are not associated with apoE genotype but with age and female sex in Alzheimer's disease. J Neurol Neurosurg Psychiatry 68(5):653656

10. Hacke W, Kaste M, Fieschi C, von Kummer R, Davalos A, Meier D, Larrue V, Bluhmki E, Davis S, Donnan G, Schneider D, DiezTejedor E, Trouillas P (1998) Randomised double-blind placebocontrolled trial of thrombolytic therapy with intravenous alteplase in acute ischemic stroke (ECASS II). Lancet. 352(9136):12451251
11. Costello C, Campbell B, de la Ossa NP, Zheng T, Sherwin J, Weir L et al (2012) Age over 80years is not associated with increased hemorrhagic transformation after stroke thrombolysis. J Clin Neurosci 19(3):360-363

12. Hachinski VC, Potter P, Merskey H (1987) Leuko-araiosis. Arch Neurol 44(1):21-23

13. Debette S, Markus HS (2010) The clinical importance of white matter hyperintensities on brain magnetic resonance imaging: systematic review and meta-analysis. BMJ 341:c3666

14. Rost NS, Rahman RM, Biffi A, Smith EE, Kanakis A, Fitzpatrick K, Lima F, Worrall BB, Meschia JF, Brown RD, Brott TG, Sorensen AG, Greenberg SM, Furie KL, Rosand J (2010) White matter hyperintensity volume is increased in small vessel stroke subtypes. Neurology 75:1670-1677

15. Willer L, Havsteen I, Ovesen C, Christensen AF, Christensen H (2015) Computed tomography-verified Leukoaraiosis is a risk factor for post-thrombolytic hemorrhage. J Stroke Cerebrovasc Dis 24(6):1126-1130

16. Neumann-Haefelin T, Hoelig S, Berkefeld J, Fiehler J, Gass A, Humpich M, Kastrup A, Kucinski T, Lecei O, Liebeskind DS, Rother J, Rosso C, Samson Y, Saver JL, Yan B, MR Stroke Group (2006) Leukoaraiosis is a risk factor for symptomatic intracerebral hemorrhage after thrombolysis for acute stroke. Stroke 37(10):2463-2466

17. Curtze S, Haapaniemi E, Melkas S, Mustanoja S, Putaala J, Sairanen T, Sibolt G, Tiainen M, Tatlisumak T, Strbian D (2015) White matter lesions double the risk of post-thrombolytic Intracerebral hemorrhage. Stroke. 46(8):2149-2155

18. Kongbunkiat K, Wilson D, Kasemsap N, Tiamkao S, Jichi F, Palumbo V, Hill MD, Buchan AM, Jung S, Mattle HP, Henninger N, Werring DJ (2017) Leukoaraiosis, intracerebral hemorrhage and functional outcome after acute stroke thrombolysis. Neurology. 88(7):638-645

19. Engelter ST, Bonati LH, Lyrer PA (2006) Intravenous thrombolysis in stroke patients of $>$ or $=80$ versus $<80$ years of age-a systematic review across cohort studies. Age Ageing 35(6):572-580

20. Yang CM, Hung CL, Su HC, Lin HJ, Chen CH, Lin CC, Hu HH, Lin SH, Sung PS (2018) Leukoaraiosis and risk of intracranial hemorrhage and outcome after stroke thrombolysis. PLoS One 13(5):e0196505

21. Clark WM, Wissman S, Albers GW, Jhamandas JH, Madden KP, Hamilton S (1999) Recombinant tissue-type plasminogen activator (Alteplase) for ischemic stroke 3 to 5 hours after symptom onset. The ATLANTIS study: a randomized controlled trial. Alteplase thrombolysis for acute noninterventional therapy in ischemic stroke. JAMA. 282(21):2019-2026

22. Furlan A, Higashida R, Wechsler L, Gent M, Rowley H, Kase C, Pessin M, Ahuja A, Callahan F, Clark WM, Silver F, Rivera F, PROACT Investigators (1999) Intra-arterial prourokinase for acute ischemic stroke. The PROACT II study: a randomized controlled trial. JAMA 282:2003-2011

23. Alshekhlee A, Mohammadi A, Mehta S, Edgell RC, Vora N, Feen E, Kale S, Shakir ZA, Cruz-Flores S (2010) Is thrombolysis safe in the elderly?: analysis of a national database. Stroke. 41(10):2259 2264

24. Mehta RH, Cox M, Smith EE, Xian Y, Bhatt DL, Fonarow GC, Peterson ED, Get With The Guidelines-Stroke Program (2014) Race/ethnic differences in the risk of hemorrhagic complications among patients with ischemic stroke receiving thrombolytic therapy. Stroke 45(8):2263-2269

25. Menon BK, Saver JL, Prabhakaran S, Reeves M, Liang L, Olson DWM, Peterson ED, Hernandez AF, Fonarow GC, Schwamm LH, Smith EE (2012) Risk score for intracranial hemorrhage in patients with acute ischemic stroke treated with intravenous tissue-type plasminogen activator. Stroke 43:2293-2299 
26. Chen Y, Yan S, Xu M, Zhong G, Liebeskind DS, Lou M (2018) More extensive white matter hyperintensity is linked with higher risk of remote intracerebral hemorrhage after intravenous thrombolysis. Eur J Neurol 25(2):380-e15

27. Charidimou A, Pasi M, Fiorelli M, Shams S, von Kummer R, Pantoni L, Rost N (2016) Leukoaraiosis, cerebral hemorrhage, and outcome after intravenous thrombolysis for acute ischemic stroke: a meta-analysis (v1). Stroke. 47(9):2364-2372

28. Nighoghossian N, Abbas F, Cho TH, Geraldo AF, Cottaz V, Janecek E, Mechtouff L, Bischoff M, el Khoury C, Schott AM, Derex L, Hermier M, Tisserand LG, Amelie R, Chamard L, Berthezene Y (2016) Impact of leukoaraiosis on parenchymal hemorrhage in elderly patients treated with thrombolysis. Neuroradiology. 58(10):961-967

29. Wardlaw JM, Smith EE, Biessels GJ, Cordonnier C, Fazekas F, Frayne R, Lindley RI, O'Brien JT, Barkhof F, Benavente OR, Black SE, Brayne C, Breteler M, Chabriat H, Decarli C, de Leeuw FE, Doubal F, Duering M, Fox NC, Greenberg S, Hachinski V, Kilimann I, Mok V, Oostenbrugge Rv, Pantoni L, Speck O, Stephan BC, Teipel S, Viswanathan A, Werring D, Chen C, Smith C, van Buchem M, Norrving B, Gorelick PB, Dichgans M, STandards for ReportIng Vascular changes on nEuroimaging (STRIVE v1) (2013) Neuroimaging standards for research into small vessel disease and its contribution to ageing and neurodegeneration. Lancet Neurol 12(8):822-838

30. Birns J, Jarosz J, Markus HS, Kalra L (2009) Cerebrovascular reactivity and dynamic autoregulation in ischaemic subcortical white matter disease. J Neurol Neurosurg Psychiatry 80(10):1093-1098
31. Moody DM, Brown WR, Challa VR, Anderson RL (1995) Periventricular venous collagenosis: association with leukoaraiosis. Radiology 194(2):469-476

32. Fernandez-Cadenas I, Mendioroz M, Domingues-Montanari S, Del Rio-Espinola A, Delgado P, Ruiz A et al (2011) Leukoaraiosis is associated with genes regulating blood-brain barrier homeostasis in ischaemic stroke patients. Eur J Neurol 18(6):826-835

33. Huisa BN, Caprihan A, Thompson J, Prestopnik J, Qualls CR, Rosenberg GA (2015) Long-term blood-brain barrier permeability changes in Binswanger disease. Stroke. 46(9):2413-2418

34. Kahles T, Foerch C, Sitzer M, Schroeter M, Steinmetz H, Rami A (2005) el ta. Tissue plasminogen activator mediated blood-brain barrier damage in transient focal cerebral ischemia in rats: relevance of interactions between thrombotic material and thrombolytic agent. Vasc Pharmacol 43(4):254-259

35. Curtze S, Melkas S, Sibolt G, Haapaniemi E, Mustanoja S, Putaala J et al (2015) Cerebral computed tomography-graded white matter lesions are associated with worse outcome after thrombolysis in patients with stroke. Stroke. 46(6):1554-1560

36. Nordahl CW, Ranganath C, Yonelinas AP, Decarli C, Fletcher E, Jagust WJ (2006) White matter changes compromise prefrontal cortex function in healthy elderly individuals. J Cogn Neurosci 18:418-429

Publisher's note Springer Nature remains neutral with regard to jurisdictional claims in published maps and institutional affiliations. 